\title{
Gene Therapy Using a miniCEP290 Fragment Delays Photoreceptor Degeneration in a Mouse Model of Leber Congenital Amaurosis
}

\author{
Wei Zhang, Linjing Li, ${ }^{1}$ Qin Su, Guangping Gao, and Hemant Khanna ${ }^{1,2, *}$ \\ ${ }^{1}$ Department of Ophthalmology and ${ }^{2}$ Horae Gene Therapy Center, UMASS Medical School, Worcester, Massachusetts.
}

Mutations in the cilia-centrosomal protein CEP290 are frequently observed in autosomal recessive childhood blindness disorder Leber congenital amaurosis (LCA). No treatment or cure currently exists for this disorder. The Cep290 ${ }^{r d 16}$ (retinal degeneration 16) mouse (a model of LCA) carries a mutation in the Cep290 gene. This mutation leads to shorter cilia formation and defective photoreceptor structure and function. A roadblock to developing a gene replacement strategy for CEP290 using conventional adenoassociated virus (AAV) vectors is its large size. The identification and characterization is reported of a miniCEP290 gene that is amenable to AAV2/8-mediated delivery and delaying retinal degeneration in the Cep290 ${ }^{r d 16}$ mice. Using the ability of Cep290 ${ }^{r d 16}$ mouse embryonic fibroblasts to from shorter cilia as a platform, a human CEP290 domain encoded by amino acids 580-1180 (miniCEP290 ${ }^{580-1180}$ ) was identified that can recover the cilia length in vitro. Furthermore, subretinal injection of AAV particles carrying the cDNA expressing miniCEP290 $0^{580-1180}$ into neonatal Cep290 ${ }^{r d 16}$ mice resulted in significantly improved photoreceptor survival, morphology, and function compared to control injected mice. These studies show the potential of using a truncated CEP290 to treat this fast progressing and devastating disease.

Keywords: cilia, retina, photoreceptor, ciliopathies, gene therapy, LCA

\section{INTRODUCTION}

THE CILIUM IS AN EVOLUTIONARILY conserved sensory organelle involved in regulating development and homeostasis. ${ }^{1}$ In the light-sensing neurons called photoreceptors (PRs), the bridge-like "connecting cilium" links the light-sensing outer segment to the protein-synthesizing inner segment. ${ }^{2}$ Mutations in the genes encoding ciliary proteins result in disorders collectively termed "ciliopathies" that can affect the retina alone or as part of a syndromic disease. ${ }^{3}$ One of the most severe forms of retinal ciliopathies is Leber congenital amaurosis (LCA). ${ }^{4}$ This disorder results in early and profound PR dysfunction and degeneration, usually beginning at birth or by around 5 years of age. CEP290 mutations are also associated with syndromic ciliopathies, including Joubert syndrome, Meckel-Gruber Syndrome, Bardet-Biedl syndrome (BBS), and Senior-Løken syndrome. ${ }^{5-10}$ No treatment or cure currently exists for such diseases. ${ }^{4}$

Mutations in the cilia-centrosomal protein encoding gene CEP290 are the most frequent cause of LCA, accounting for $>25 \%$ of LCA (LCA10; OMIM 611755). ${ }^{11}$ It has been demonstrated that CEP290 is involved in regulating the cilia assembly program. Mouse embryonic fibroblasts (MEFs) derived from a Cep290-mutant (Cep290 ${ }^{\text {rd16}}$ ) mouse model of LCAlike PR degeneration ${ }^{12}$ have fewer ciliated cells and form shorter cilia. ${ }^{13}$ Moreover, the CEP290-associated disease is likely due to reduction or the loss of normal protein function. ${ }^{6,14-16}$ Although antisense oligonucleotides and genome editing have been used to correct a common intronic mutation in CEP290, both are mutation-dependent approaches. ${ }^{17-20}$ Lentivirusmediated delivery of the full-length (FL) CEP290 into patient-derived fibroblasts was also shown to rescue the CEP290-associated defect in vitro. ${ }^{13}$

${ }^{*}$ Correspondence: Dr. Hemant Khanna, Department of Ophthalmology and Visual Sciences, Horae Gene Therapy Center, Albert Sherman Center AS6-2043, UMASS Medical School, Worcester, MA 01605.E-mail: hemant.khanna@umassmed.edu

(c) Wei Zhang et al. 2018; Published by Mary Ann Liebert, Inc. This article is available under the Creative Commons License CC-BY-NC (http://creativecommons.org/licenses/by-nc/4.0). This license permits non-commercial use, distribution and reproduction in any medium, provided the original work is properly cited. Permission only needs to be obtained for commercial use and can be done via RightsLink. 
However, its efficacy and long-term safety have not been demonstrated in vivo.

Recent studies have reported the development and characterization of several vertebrate models of Cep290. Mice generated either using gene trap alleles or by creating a null allele within exons 1-4 or exons 36-37 of mouse Cep290 recapitulate the phenotypes associated with syndromic ciliopathies. ${ }^{21-23}$ However, they are not ideal model systems to investigate nonsyndromic LCA due to CEP290 mutations. Earlier studies also identified a naturally occurring feline model of retinal degeneration due to CEP290 mutation in exon 50. As predicted, this model undergoes relatively delayed and late onset form of retinal degeneration. ${ }^{24}$

The identification and characterization of a naturally occurring mouse mutant of Cep290, termed Cep290 ${ }^{\text {rd16 }}$, was previously reported. ${ }^{12}$ This mutant carries an in-frame deletion within exons 37-41 of mouse Cep290, which encodes a part of the myosintail homology domain (deleted aa 1606-1904). The deletion results in the production of a truncated CEP290 variant, which is partially functional. The Cep290 ${ }^{\text {rd16 }}$ mouse exhibits non-syndromic retinal degeneration, which mimics the LCA onset and phenotype observed in patients. ${ }^{12,25}$ Moreover, the region of the human CEP290 gene that is homologous to the domain deleted in the Cep290 ${ }^{\text {rd16 }}$ mouse harbors LCA-causing mutations. Thus, the Cep290 ${ }^{\text {rd16 }}$ mice provide an excellent platform to initiate therapeutic investigations.

Adeno-associated virus (AAV) vector-mediated delivery of the transgene into the subretinal space is a safe and effective approach to treat PR degenerative diseases. ${ }^{26-30}$ However, a roadblock in AAVmediated CEP290 delivery is the size of the CEP290 cDNA ( $\sim 8 \mathrm{~kb})$, which exceeds the transgene packaging capacity of the conventional AAV vectors $(\sim 4.0 \mathrm{~kb}) .{ }^{31}$ This study was undertaken to engineer AAV-amenable miniCEP290 genes encoding functionally optimized proteins, as described previously for muscular dystrophy causing gene dystrophin. ${ }^{32}$ The studies provide evidence for the suitability of using miniCEP290 as a readily translatable paradigm for CEP290-LCA.

\section{MATERIALS AND METHODS}

\section{Plasmid constructs and AAV production}

For in vitro experiments, FL or miniCEP290expressing cDNAs were cloned into a pEGFP-C1 plasmid expressing GFP-tagged proteins under the control of a CMV promoter. For AAV production, the miniCEP290-encoding cDNAs were cloned into a pAAV2 vector plasmid between a CMVenhancer/
CBA (chicken $\beta$-actin) promoter upstream of the internal ribosome entry site (IRES) GFP and $\beta$ globin intron. This expression cassette was flanked with AAV2 inverted terminal repeats (ITRs). The recombinant AAV2 genomes were packaged with AAV8 capsid by HEK293-triple transfection method and purified by $\mathrm{CsCl}$ gradient centrifugation method, as previously described. ${ }^{33}$

\section{Cell culture, transient transfection, and immunostaining}

MEFs derived from wild-type (WT) and Cep290 ${ }^{\text {rd } 16}$ mice were maintained in Dulbecco's modified Eagle's medium with $10 \%$ fetal bovine serum. Transient transfection with GFP-CEP290-FL or GFPminiCEP290s was performed using Lipofectamine 2000 (Thermo Fisher). The transfected cells were either harvested for immunoblotting or were serum starved to induce cilia growth, as described. ${ }^{34}$ The ciliated cells were then immunostained and imaged under a Leica microscope (DM5500). The cilia length was measured by using Image J. The pixel values of cilia length were transformed into actual length using the Leica Application Suite. The relationship between pixel length and actual length at $63 \times$ magnification is: 680 pixels $=100 \mu \mathrm{m}$.

\section{Subretinal injection}

All animal studies were approved by the Institutional Animal Care and Use Committee of the UMASS Medical School. The WT C57BL6/J mice were obtained from Jackson Laboratories. The Cep290 ${ }^{\text {rd16 }}$ mice have been described previously. ${ }^{12}$ The Cep290 ${ }^{r d 16}$ mouse pups (P0/P1) were subretinally injected unilaterally with $8 \times 10^{9} \mathrm{vg} / \mu \mathrm{L}$ (total volume $1 \mu \mathrm{L}$ ) of the virus. ${ }^{35,36}$

\section{Electroretinogram and immunofluorescence microscopy of the retina}

Scotopic and photopic electroretinograms (ERGs) were performed, as previously reported. ${ }^{37}$ For scotopic response, mice were dark adapted overnight, and all procedures were performed under dim red light. The dark-adapted ERG protocol consisted of five steps with increasing stimulus intensities from 0.009 to $100 \mathrm{~cd} . \mathrm{s} / \mathrm{m}^{2}$, with a mixed white light (white 6,500 K; ColorDome; Diagnosys LLC). The flash frequency was $0.07 \mathrm{~Hz}$ for bright flashes and up to $0.5 \mathrm{~Hz}$ for dim flashes. Averages ranged from 10 trials for dim flashes to five trials for bright flashes. Light-adapted (photopic) ERGs were recorded after light adaptation with a background illumination of $30 \mathrm{~cd} / \mathrm{m}^{2}$ (white $6,500 \mathrm{~K}$ ) for $8 \mathrm{~min}$.

Immunofluorescence microscopy was performed essentially as described. ${ }^{37}$ In brief, retinal cryosec- 
tions were stained with primary antibodies: rhodopsin (mouse monoclonal; EMD Millipore), M-opsin (rabbit polyclonal; EMD Millipore), and peripherinretinal degeneration slow (RDS; mouse monoclonal; gift from Dr. Muna Naash), ARL13B (rabbit polyclonal; Abcam), GFP (chicken polyclonal; Abcam), and $\gamma$-tubulin (mouse monoclonal; Sigma-Aldrich). After washing with phosphate-buffered saline, Alexa488 or Alexa-546 or Alexa-633-conjugated secondary antibodies were added, and the sections were further incubated for $1 \mathrm{~h}$. After washing, nuclei were stained with DAPI, and cells were imaged using a Leica microscope (DM5500).

\section{Statistical analysis}

All data are presented as means \pm standard error of the mean. Data groups were compared by Student's $t$-tests using the SigmaPlot software. Differ- ences between groups were considered statistically significant if $p<0.05$. The statistical significance is denoted with asterisks $(* p<0.01-0.05 ; * * p<0.001-$ $0.01 ; * * * p<0.0001-0.001)$.

\section{RESULTS \\ Construction and in vitro functional potential of miniCEP290s}

The human CEP290 gene consists of 52 exons, which encode a protein of $\sim 290 \mathrm{kDa}(2,479$ amino acids). Based on the previous studies on the involvement of the different CEP290 domains in its interactions and ciliary localization, ${ }^{12,14,38-42}$ plasmids encoding GFP-fused human miniCEP290 ${ }^{580-1695}$, miniCEP2901751-2050 and miniCEP290 $2037-2479$ were constructed (Fig. 1A). To test the functional potential of the miniCEP290s, a surrogate assay system was
A
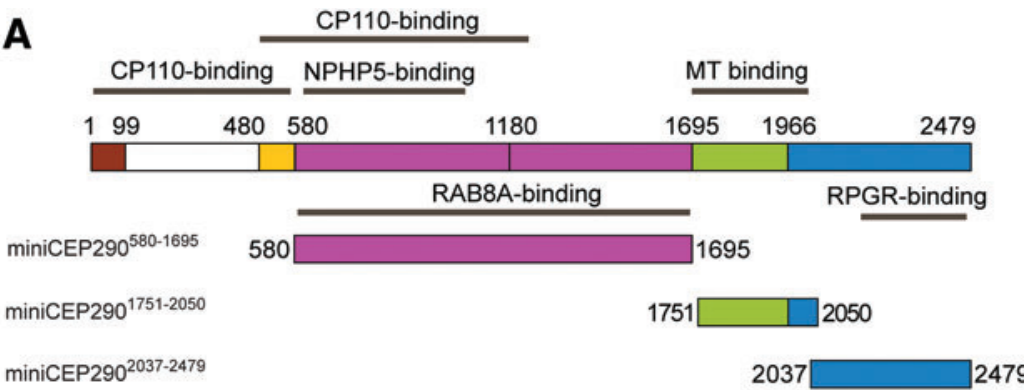

B

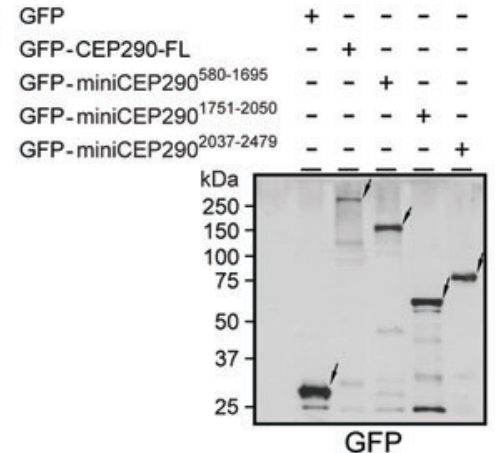

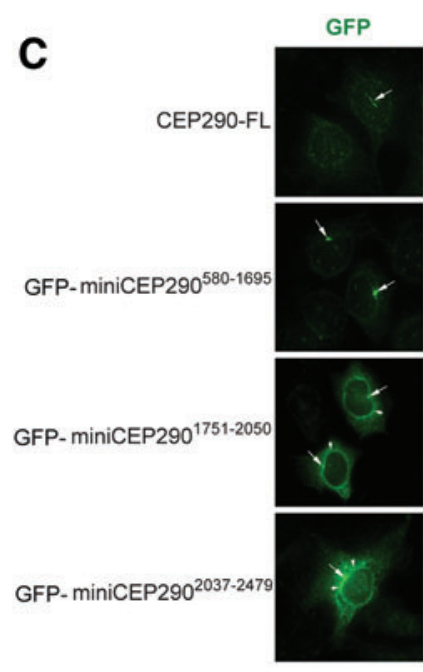
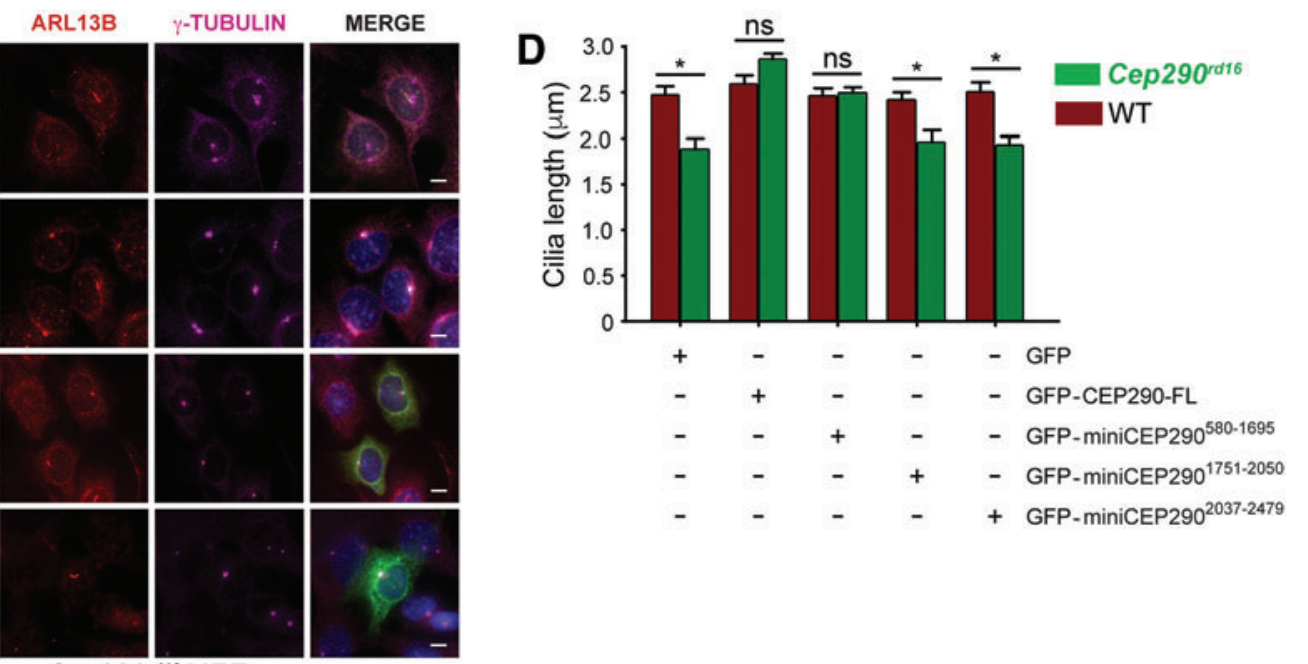

Cep290'di6 MEFs

Figure 1. Generation of miniCEP290s. (A) Schematic representation of the full-length CEP290 protein depicts the location of the distinct protein interaction domains. The regions used in generating the miniCEP290s are also indicated. MT, microtubule-binding domain. (B and C) The Cep290'd16 mouse embryonic fibroblasts (MEFs) were transiently transfected with plasmids encoding GFP-fused full-length CEP290 or indicated miniCEP290s. The cells were then processed for immunoblot analysis using protein extracts $(50 \mu \mathrm{g}$ ) analyzed by GFP antibody (B), or immunofluorescence analysis using GFP (green), ARL13B (red; ciliary marker), and $\gamma$-tubulin ( pink, basal body) antibodies (C). Scale bar: $10 \mu \mathrm{m}$. Nuclei were stained with DAP1 (blue). Arrows in (B) depict the GFP-CEP290 immunoreactive bands. Molecular weight markers are shown in $\mathrm{kDa}$. Longer arrows in (C) indicate the CEP290-immunoreactive signal, whereas shorter arrows depict cytoplasmic staining of the truncated CEP290. (D) Cilia length was quantified in the Cep290 ${ }^{\text {rd16 }}$ (green bars) or wild type (WT; red bars) MEFs expressing GFP, GFP-CEP290-FL, or indicated miniCEP290s. ${ }^{*} p<0.01$; ns, not significant. Color images available online at www.liebertpub.com/hum 
designed using Cep290 ${ }^{r d 16}$ MEFs. First, the expression and localization of the different miniCEP290s in the Cep290 ${ }^{r d 16}$ MEFs were investigated. The analysis revealed that the FL CEP290 and all CEP290 domains expressed at comparable levels in the MEFs (Fig. 1B). Additional bands observed in the immunoblot most likely represent degradation products of the fusion protein. In addition to GFP-CEP290FL, miniCEP290 ${ }^{580-1695}$ showed a predominant localization to the base of cilia (co-localization with $\gamma$-tubulin) and proximal cilia (co-localization with ADP-Ribosylation Factor-Like 13B; ARL13B; ciliary marker; Fig. 1C). Other variants showed a relatively diffuse pattern of localization. Next, the ability of the miniCEP290s to modulate cilia length in the Cep290 ${ }^{\text {rd16 }}$ MEFs was assessed. Cilia of Cep290 ${ }^{\text {rd16 }}$ MEFs are around $1.7 \mu \mathrm{m}$ in length compared to controls, which have around $2.7 \mu \mathrm{m}$ long cilia. Cilia length of the Cep290 ${ }^{\text {rd16 }} \mathrm{MEFs}$ was significantly increased when either FL GFPCEP290 or GFP-miniCEP290 ${ }^{580-1695}$ was expressed. Other variants and the plasmid expressing only GFP did not change the cilia length. No effect on the cilia length of the WT MEFs was observed (Fig. 1D).

Next, it was asked whether further shortening of miniCEP290 ${ }^{580-1695}$ would also result in a cilia length rescue. To this end, plasmids encoding GFP-miniCEP290 ${ }^{580-1180}$ and miniCEP290 ${ }^{1181-1695}$ were constructed. Both variants exhibited optimal expression, as determined by immunoblot- ting using GFP antibody (Fig. 2A). Additional degraded products of the fusion protein were also detected using the GFP antibody. While GFPminiCEP290 $0^{580-1180}$ localized predominantly to the cilia, miniCEP290 ${ }^{1181-1695}$ exhibited a relatively diffuse localization in the cytosol with some ciliary localization (Fig. 2B). Cilia rescue assay showed that expression of either variant resulted in a comparable and significant increase in the cilia length of the Cep290 ${ }^{\text {rd16 }}$ MEFs (Fig. 2C). Based on these results, miniCEP290 ${ }^{580-1180}$ and miniCEP290 $0^{1181-1695}$ were selected for further studies.

\section{Effect of miniCEP290 injection on PR function}

We cloned miniCEP290 $0^{580-1180}$, mini CEP290 ${ }^{1181-1695}$, and miniCEP290 $2037-2479$ (as negative control) into AAV2 vector genome with ubiquitously expressed CMVenhancer/CBA (chicken $\beta$-actin) promoter containing the IRES between the gene of interest and GFP. The IRES permits translation of CEP290 and GFP from a single bicistronic mRNA, which assists in identifying the transduced cells using GFP antibody. To assess the effect of GFP expression, we also used AAV2-GFP expressing construct as control. The viruses were packaged in AAV8 capsid, which is shown to transduce PRs efficiently. ${ }^{43}$ The viruses were injected at $8 \times 10^{9} \mathrm{vg} /$ eye into the subretinal space of Cep290 ${ }^{\text {rd16 }}$ pups at $\mathrm{P} 0 / \mathrm{P} 1$. Similar doses have been successfully used to treat retinal degeneration in mice. ${ }^{44}$ Injections at higher doses resulted in toxicity (data not shown).
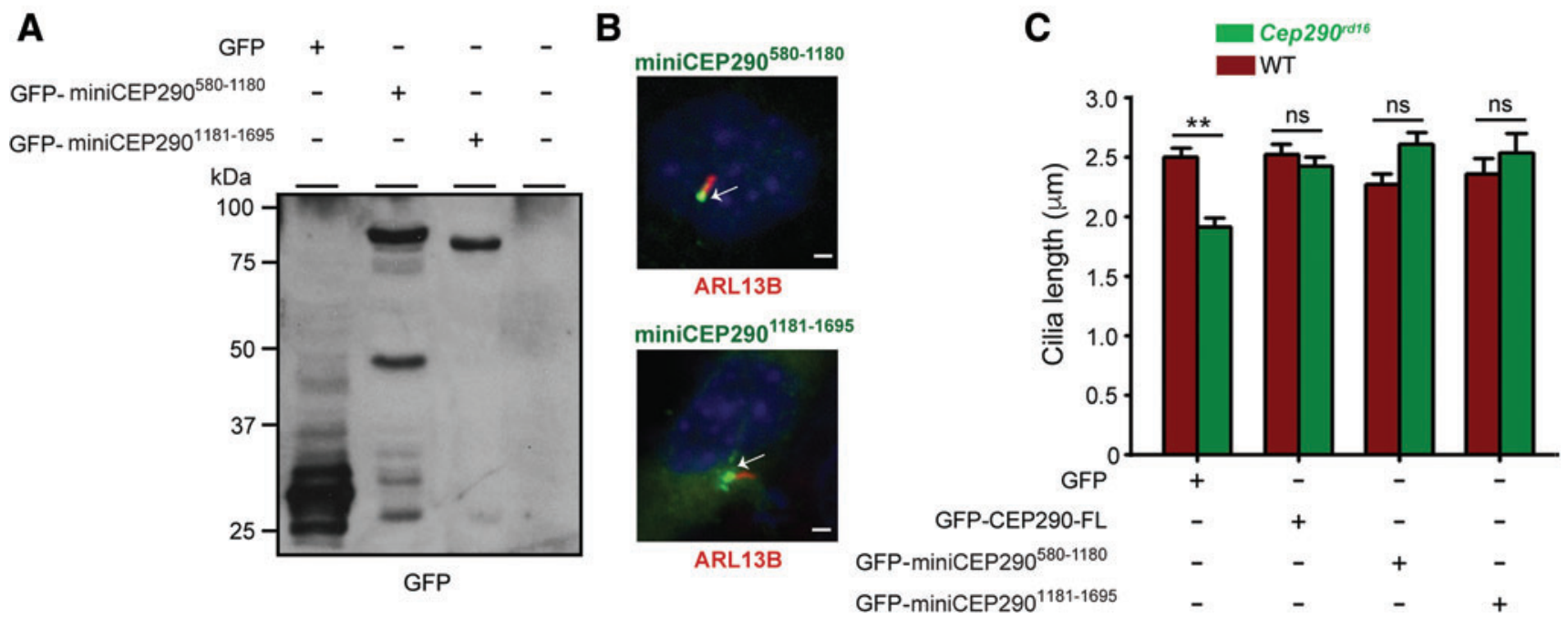

Figure 2. In vitro rescue potential of miniCEP290 $580-1180$. (A) Protein extracts $(50 \mu \mathrm{g})$ from Cep290 ${ }^{\text {rd16 }}$ MEFs transiently transfected with plasmids encoding GFP, GFP-miniCEP290 $0^{580-1180}$, or GFP-CEP290 ${ }^{1181-1695}$ were analyzed by immunoblot analysis using GFP antibody. Arrows indicate GFP-miniCEP290 specific immunoreactive bands. Molecular weight markers are shown in $\mathrm{kDa}$. (B) Cep290 ${ }^{\text {rd16 }} \mathrm{MEFs}$ expressing the indicated miniCEP290s were stained with GFP (green) and ARL13B (red) antibodies. Nuclei were stained with DAPI (blue). Arrows indicate predominant localization of GFP signal at the proximal region of cilia. Additional cytoplasmic staining of GFP was consistently detected in cells expressing GFP-miniCEP2901181-1695. Scale bar: $2 \mu \mathrm{m}$. (C) Cilia length of WT or Cep290 ${ }^{\text {rd16 }}$ MEFs expressing the indicated proteins was quantified. ${ }^{*} p<0.01$. Color images available online at www.liebertpub.com/hum 
Analysis of PR function by ERG at 3 weeks post injection revealed improvement (25-30\%) in both scotopic (rod PR-mediated) and photopic (cone PR-mediated) responses of the miniCEP290 ${ }^{580-1180}$ injected mice (Fig. 3A-C). The miniCEP290 ${ }^{1181-1695}$ injected mice revealed a relatively mild improvement in the outer nuclear layer preservation (Supplementary Fig. S1A and B; Supplementary Data are available online at www.liebertpub.com/hum) and scotopic and photopic ERG amplitudes (Supplementary Fig. S1C and D). No improvement was detected using miniCEP290 $2037-2479$ or GFP (Fig. 3). Age-matched uninjected mice were also used as controls. Further analysis revealed that the improvement in the ERG was stable up to 4 weeks and exhibited significantly decreased amplitudes at 5 and 8 weeks post injection (Fig. 3D). Although in vitro cilia length rescue assay showed similar rescue effect with both miniCEP290 $280-1180$ and miniCEP2901181-1695 minigenes, the miniCEP290 $0^{580-1180}$ is more potent in vivo. Such results show that in vivo experiments are important to validate the in vitro data, and indicate the existence of domain-specific functions of CEP290.

\section{Effect of miniCEP290 $580-1180$ on retinal morphology}

To assess the effect of miniCEP290 injections on retinal morphology, retinal cryosections were used in which the injected regions were identified by staining with GFP antibody. The number of layers of the outer nuclear layer correlates with PR survival. The following were found: around six or seven layers in the Cep290 ${ }^{\text {rd16 }}$ retinas injected with miniCEP290 ${ }^{580-1180}$ and two to three layers in retinas injected with miniCEP290 $2037-2472$ or GFP (equivalent to uninjected Cep290 ${ }^{\text {rd16 }}$ at 3 weeks of age; Fig. 4A). The number of layers in the outer nuclear layer progressively declined with age (Fig. 4B). Morphological analysis using ultrathin sections of the Cep290 ${ }^{r d 16}$ retinas injected with miniCEP290 ${ }^{580-1180}$ exhibited significant preservation of the outer nuclear layer at 3 weeks of age (Fig. 4C).

Next, the structural preservation of the PR outer segment was examined in the miniCEP290 ${ }^{580-1180}$ injected mice by staining with peripherin-RDS (PR outer segment marker ${ }^{45}$ ). RDS is a structural protein that specifically localizes to the outer segment discs and maintains the OS structure. The miniCEP290 ${ }^{580-1180}$-injected Cep290 ${ }^{\text {rd16 }}$ mice exhibited improved RDS localization to the outer segment compared to undetectable RDS expression in the GFP-injected mice (Fig. 4D; red staining).
The expression of rhodopsin and cone opsins, two of the key phototransduction proteins, was also examined. As predicted, there was undetectable opsin expression in the miniCEP290 $2037-2479$-injected retinas. However, the miniCEP290 ${ }^{580-1180}$-injected retinas revealed detectable expression of rhodopsin and cone opsins in the outer segments (Fig. 5). Some staining of cone opsins in the inner segment and outer nuclear layer was also observed. Overall, the results suggest that the expression of miniCEP290 ${ }^{580-1180}$ can improve the function, morphology, and opsin trafficking of the Cep290 ${ }^{\text {rd16 }}$ retinas.

\section{DISCUSSION}

Recent reports on the success of clinical trials of gene therapy for RPE65-LCA and choroideremia have provided considerable excitement in the field of $\mathrm{AAV}$-mediated gene delivery into the diseased retina. ${ }^{28,30,46}$ However, progress in the development of mutation-independent gene replacement strategies for CEP290-LCA has been delayed largely because of unsuitability of the long CEP290 gene to be packaged into conventional AAV vector system for gene therapy. This study reports the generation and potential of a truncated CEP290 domain (miniCEP290 ${ }^{580-1180}$ ) to mitigate associated retinal degeneration. The studies provide the necessary first step to initiate the development of miniCEP290 strategy for tackling associated retinal ciliopathies, as well as systemic ciliopathies due to CEP290 mutations. ${ }^{47}$ Taken together, evidence is provided for slowing down of the severe retinal degeneration using $\mathrm{AAV}$-mediated delivery of a CEP290 minigene.

Although the scotopic and photopic ERG amplitudes and PR survival improved in the miniCEP290 ${ }^{580-1180}$-treated retinas, they did not reach the levels of the WT mice. Moreover, the improvement declined with age. Such observations suggest that although the use of miniCEP290 ${ }^{580-1180}$ can be useful, additional analyses are needed to generate a more potent miniCEP290 that can mitigate CEP290-associated retinal degeneration in a diseased retina.

While the mechanism of action of miniCEP290 ${ }^{580-1180}$ is currently unclear, the findings reveal the potential of the miniCEP290 to compensate partially for the hypomorphic $\triangle \mathrm{CEP} 290$ in the Cep290 ${ }^{\text {rd16 }}$ mouse. ${ }^{12}$ Although the $\Delta$ CEP290 protein carries the domain encompassing 580-1180, the conformation of the resultant protein may no longer be functionally active. Supplementing the Cep $290^{\text {rd16 }}$ retina with aa 580-1180 likely provides the functional 

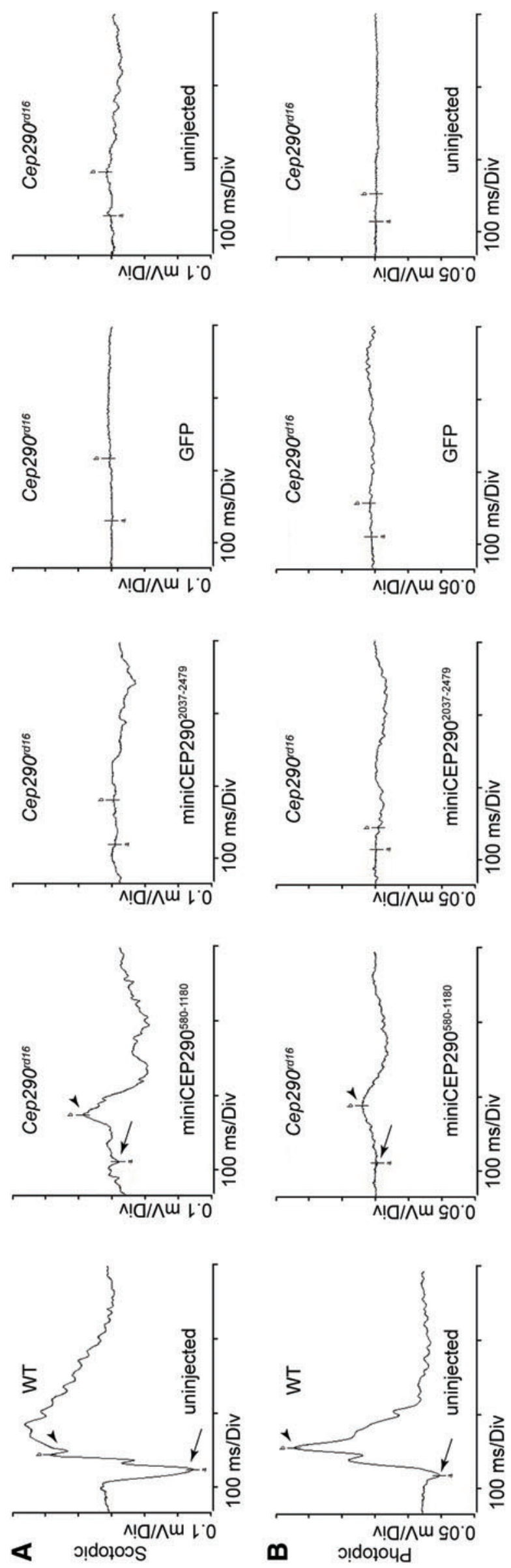
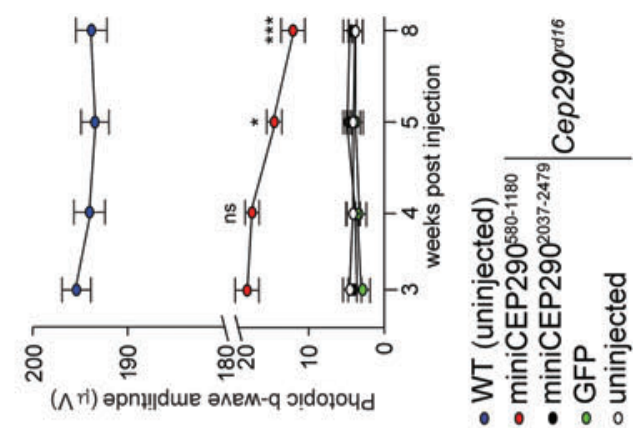

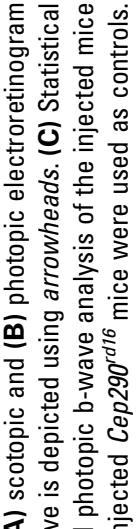

这空高竞

表家

중

元 今ै

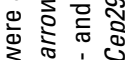

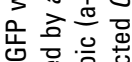

형

品

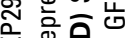

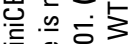

ह

行

紫嵒絭

产岸苧

䍡密

क力 흐웡

동ㅎㅁ

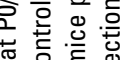

这.

흥

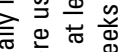

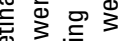

要

的定要

石言

는

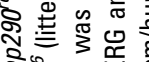

هㅇㅇㅇㅇㅇ

. D

过

혀잉

岀々产言

䏠主

过

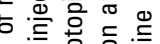

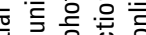

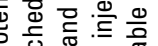

政焉

E $\stackrel{2}{2}$

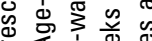

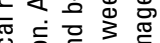

는

응 후

品

言范

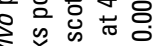

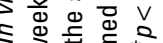

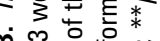

कै

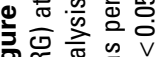




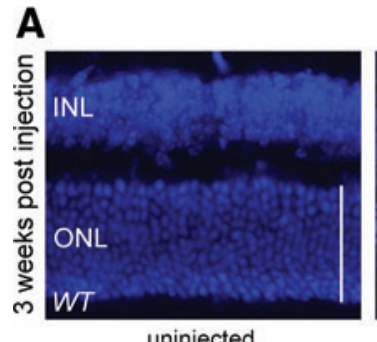

uninjected

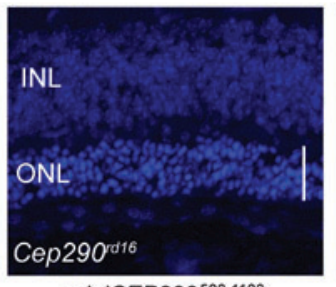

miniCEP290 $580-1180$

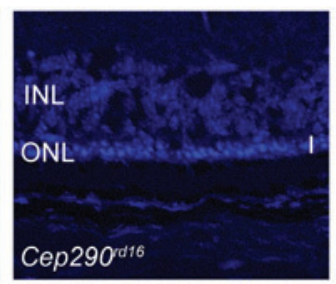

miniCEP2902037-2479

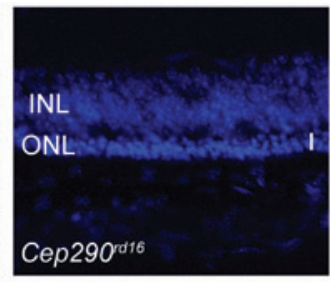

GFP

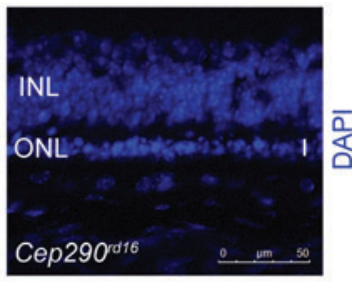

uninjected

C

3 weeks post injection
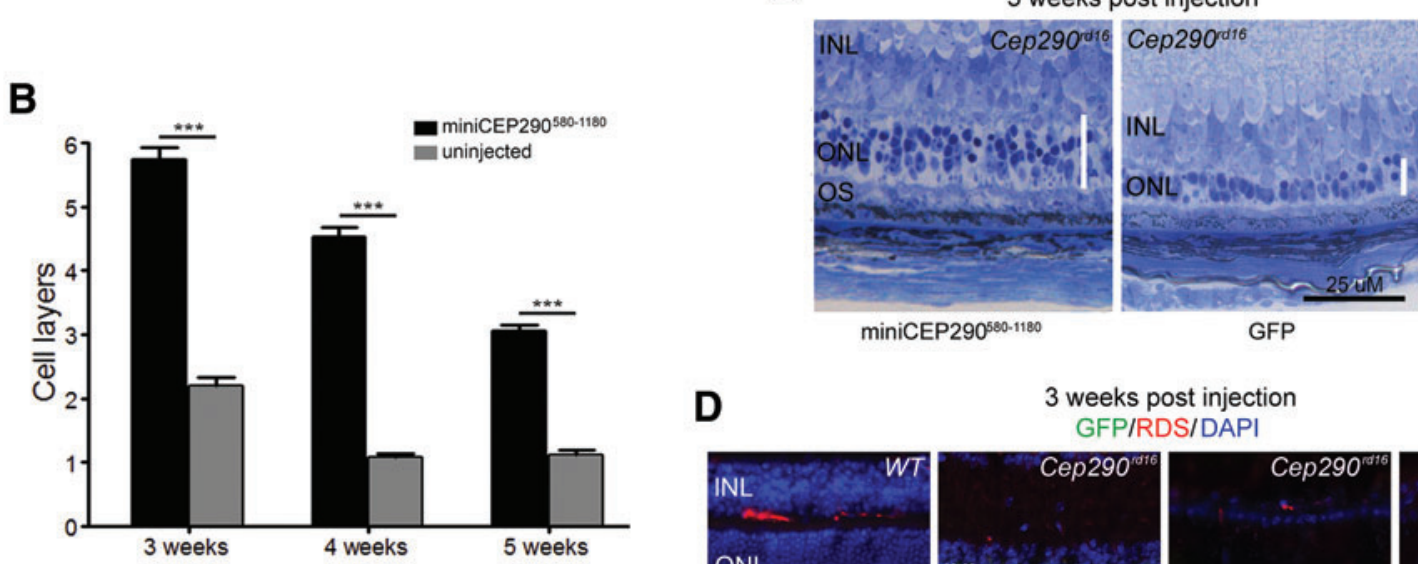

D

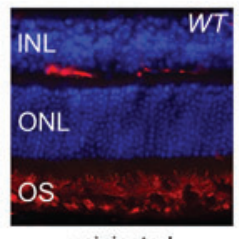

uninjected

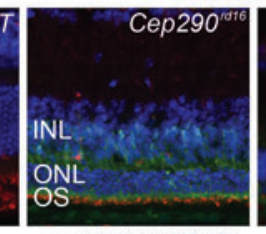

miniCEP290580-1180
3 weeks post injection GFP/RDS/DAPI

Figure 4. In vivo morphological rescue potential of miniCEP290 ${ }^{580-1180}$. Cep290 ${ }^{\text {rd16 }}$ retinas injected with indicated miniCEP290, GFP, or uninjected Cep290 ${ }^{\text {rd16 }}$ were stained with DAPI (blue) (A). The outer nuclear layer (ONL) is marked with vertical lines. WT retinal section is shown for comparison. INL, inner nuclear layer. (B) Quantification of the ONL thickness by counting the number of layers of the vector transduced region of the injected Cep290' 16 mice compared to uninjected retinas is represented. There is initial preservation of the number of layers, but progressive decline is detected with age. ${ }^{* * *} p<0.0001$. (C) The injected $C e p 290^{\text {rd16 }}$ mouse retinas were also examined by ultrathin sectioning to assess morphological preservation at 3 weeks post injection. The ONL is marked with vertical lines. The outer segment (OS) layer is clearly visible in the miniCEP290 ${ }^{580-1180}$ injected retinas. (D) Improved expression of RDS (red) is detected in the miniCEP290 ${ }^{580-1180}$ injected Cep290 ${ }^{r d 16}$ mice. Staining with GFP (green) marked the injected regions. Color images available online at www.liebertpub.com/hum

complementation needed to overcome the ciliary defect. These observations suggest that the CEP290 protein is modular and demonstrates flexibility in the protein structure-function relationship. This is also evident from the associated diverse phenotypes associated with Cep290 mutant mice. While the Cep290 ${ }^{\text {rd16 }}$ mice exhibit predominantly retinal degenerative and other sensory defects, the Cep290 ${ }^{g t}$ and Cep290 ${ }^{k o}$ mice manifest systemic disorders. ${ }^{21-23,38}$ Additional investigations are necessary to facilitate the generation of miniCEP290s that can mitigate systemic CEP290-ciliopathies. Nonetheless, the generation of partly functional PR outer segments provides a stepping stone to develop long-term disease correction when the therapy is initiated after disease onset. Further studies will focus on improving the efficacy of the miniCEP290s to mitigate associated retinal ciliopathy.

This work provides a strategy to tackle the critical roadblock in designing a suitable gene thera- peutic strategy for CEP290-LCA by developing a mutation-independent approach. The relative sparing of the central cone-rich region of the CEP290-LCA patient retinas, ${ }^{25}$ such as in NPHP5$\mathrm{LCA},{ }^{48}$ suggests that gene therapy in this region can be a viable option. However, there is dramatically reduced cone function in patients. Further investigations are needed to test the effect of miniCEP290s in dysfunctional CEP290-mutant cones, likely using larger animal models (such as cat) ${ }^{24,49}$ and cone-rich models. ${ }^{50}$

The use of minigenes as a therapeutic strategy is a viable option for delivering large genes, as has been demonstrated for dystrophin. ${ }^{32}$ Although lentiviral and nanoparticle-based delivery strategies for large genes, including $A B C A 4$ (Stargardt disease) and Usher Syndrome genes, are also being investigated, ${ }^{51,52}$ the minigene approach offers a relatively faster and translatable paradigm for tackling such disorders. 


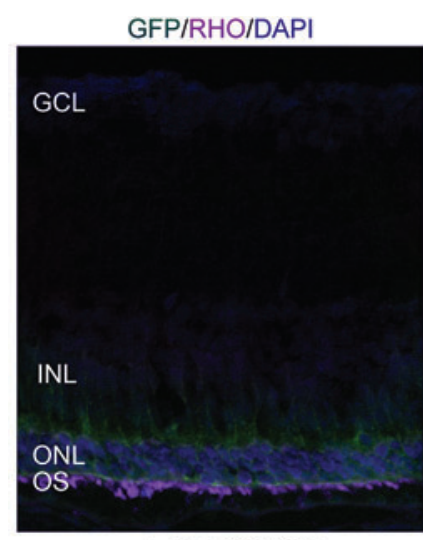

miniCEP290 $580-1180$

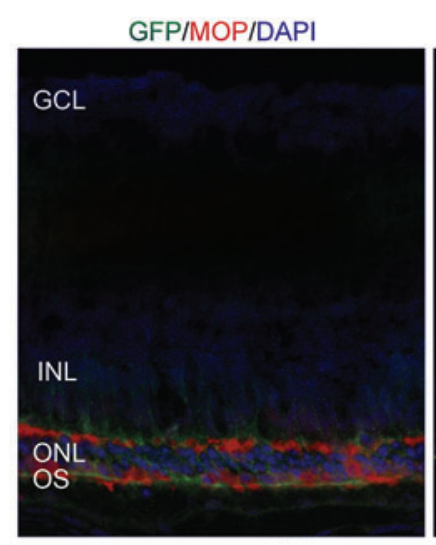

miniCEP290 $280-1180$

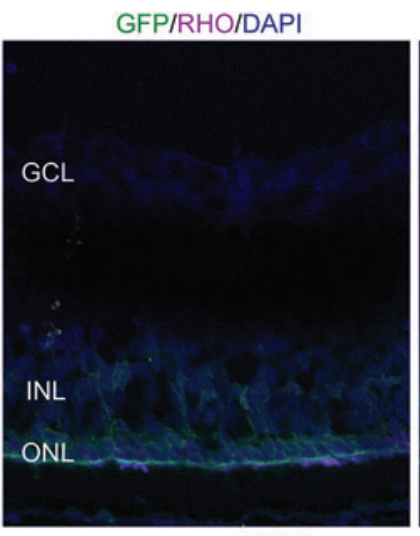

miniCEP2902037-2479

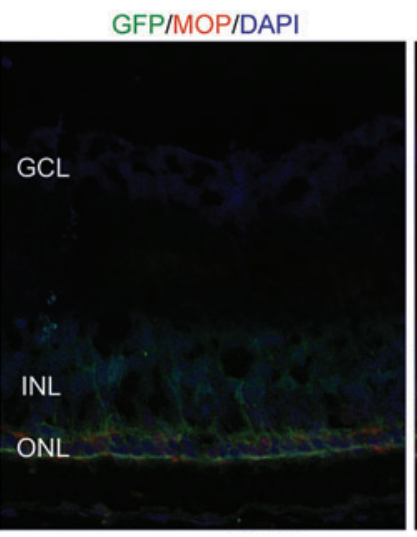

miniCEP290 2037-2479

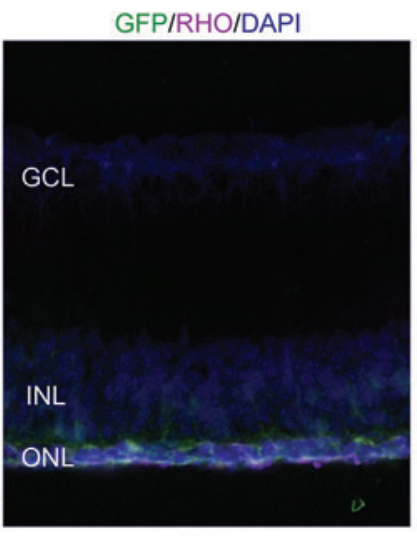

GFP

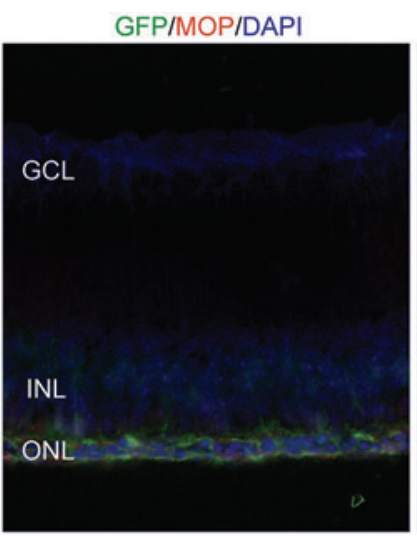

GFP

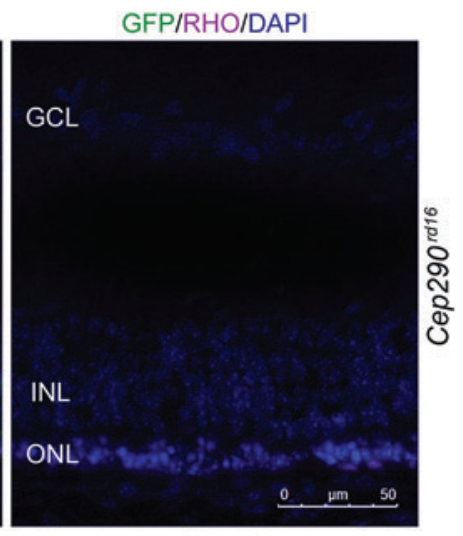

uninjected

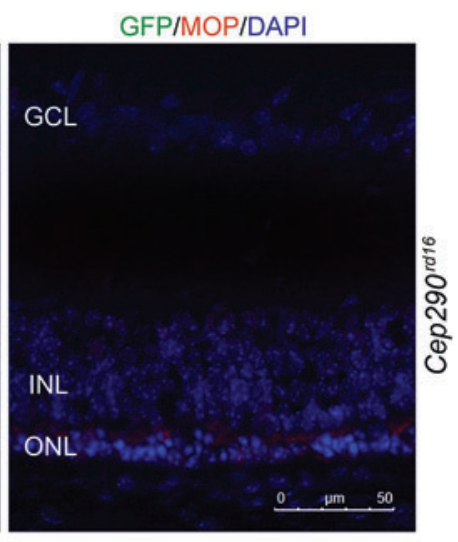

uninjected

Figure 5. Opsin trafficking in miniCEP290 ${ }^{580-1180}$-injected retinas. Retinal cryosections of Cep290 ${ }^{\text {rd16 }}$ mice injected with the indicated miniCEP290s were stained with GFP (injected regions; green), rhodopsin (RHO; purple; rod-specific; A), or M-opsin (MOP; red; cone-specific; B) antibodies and DAPI (blue; nuclei). OS-enriched opsin staining is detected in the miniCEP290 $0^{580-1180}$-injected retinas. Dramatically reduced expression of opsins is detected in the miniCEP2902037${ }^{2479}$-injected retinas. GCL, ganglion cell layer. Color images available online at www.liebertpub.com/hum

\section{ACKNOWLEDGMENTS}

This work is supported by grants from the National Institutes of Health (EY022372; H.K.), Foundation Fighting Blindness (to H.K.), and University of Massachusetts Center for Clinical and Translational Sciences (to H.K.), Public Health Service grants 1R01NS076991-01, P01AI10026301 and 1 P01 HL131471-01 from National Institutes of Health to G.G. We also thank Drs. Gregory Pazour and George Witman for helpful discussions, and Manisha Anand for technical help during the studies.

\section{AUTHOR DISCLOSURE}

G.G. is a co-founder of Voyager Therapeutics and holds equity in the company, and is an inventor listed on patents with potential royalties licensed to Voyager Therapeutics and other biopharmaceutical companies. The remaining authors have nothing to disclose.

\section{REFERENCES}

1. Eggenschwiler JT, Anderson KV. Cilia and developmental signaling. Annu Rev Cell Dev Biol 2007; 23:345-373

2. Khanna $H$. Photoreceptor sensory cilium: traversing the ciliary gate. Cells 2015;4:674-686.

3. Badano JL, Mitsuma N, Beales PL, et al. The ciliopathies: an emerging class of human genetic disorders. Annu Rev Genomics Hum Genet 2006;7:125-148.
4. den Hollander Al, Roepman R, Koenekoop RK, et al. Leber congenital amaurosis: genes, proteins and disease mechanisms. Prog Retin Eye Res 2008;27:391-419.

5. Sayer JA, Otto EA, O'Toole JF, et al. The centrosomal protein nephrocystin-6 is mutated in Joubert syndrome and activates transcription factor ATF4. Nat Genet 2006;38:674-681.
6. Anand M, Khanna $H$. Ciliary transition zone (TZ) proteins RPGR and CEP290: role in photoreceptor cilia and degenerative diseases. Expert Opin Ther Targets 2012;16:541-551.

7. Baala L, Audollent S, Martinovic J, et al. Pleiotropic effects of CEP290 (NPHP6) mutations extend to Meckel syndrome. Am J Hum Genet 2007;81:170-179. 
8. Helou J, Otto EA, Attanasio M, et al. Mutation analysis of NPHP6/CEP290 in patients with Joubert syndrome and Senior-Loken syndrome. J Med Genet 2007;44:657-663.

9. McEwen DP, Koenekoop RK, Khanna $\mathrm{H}$, et al. Hypomorphic CEP290/NPHP6 mutations result in anosmia caused by the selective loss of $\mathrm{G}$ proteins in cilia of olfactory sensory neurons. Proc Natl Acad Sci U S A 2007;104:15917-15922.

10. Valente EM, Silhavy JL, Brancati F, et al. Mutations in CEP290, which encodes a centrosomal protein, cause pleiotropic forms of Joubert syndrome. Nat Genet 2006;38:623-625.

11. den Hollander Al, Koenekoop RK, Yzer S, et al. Mutations in the CEP290 (NPHP6) gene are a frequent cause of Leber congenital amaurosis. Am J Hum Genet 2006;79:556-561.

12. Chang $B$, Khanna $H$, Hawes $N$, et al. In-frame deletion in a novel centrosomal/ciliary protein CEP290/ NPHP6 perturbs its interaction with RPGR and results in early-onset retinal degeneration in the rd16 mouse. Hum Mol Genet 2006;15:1847-1857.

13. Burnight ER, Wiley LA, Drack AV, et al. CEP290 gene transfer rescues Leber congenital amaurosis cellular phenotype. Gene Ther 2014;21:662-672.

14. Rao KN, Zhang W, Li L, et al. Ciliopathyassociated protein CEP290 modifies the severity of retinal degeneration due to loss of RPGR. Hum Mol Genet 2016;25:2005-2012.

15. Subramanian B, Anand M, Khan NW, et al. Loss of Raf-1 kinase inhibitory protein delays early-onset severe retinal ciliopathy in Cep290rd16 mouse. Invest Ophthalmol Vis Sci 2014;55:5788-5794.

16. Craige B, Tsao CC, Diener DR, et al. CEP290 tethers flagellar transition zone microtubules to the membrane and regulates flagellar protein content. J Cell Biol 2010;190:927-940.

17. Garanto A, Chung DC, Duijkers L, et al. In vitro and in vivo rescue of aberrant splicing in CEP290associated LCA by antisense oligonucleotide delivery. Hum Mol Genet 2016;25:2552-2563.

18. Collin RW, den Hollander Al, van der Velde-Visser SD, et al. Antisense oligonucleotide (AON)-based therapy for Leber congenital amaurosis caused by a frequent mutation in CEP290. Mol Ther Nucleic Acids 2012;1:e14

19. Li L, Khanna H. Stem cells with a view: a look inside a retinal ciliopathy. Stem Cell Inv 2016;3:62-64.

20. Parfitt DA, Lane A, Ramsden CM, et al. Identification and correction of mechanisms underlying inherited blindness in human iPSC-derived optic cups. Cell Stem Cell 2016;18:769-781.

21. Hynes AM, Giles RH, Srivastava $S$, et al. Murine Joubert syndrome reveals Hedgehog signaling defects as a potential therapeutic target for nephronophthisis Proc Natl Acad Sci U S A 2014;111:9893-9898.

22. Rachel RA, Yamamoto EA, Dewanjee MK, et al. CEP290 alleles in mice disrupt tissue-specific cilia biogenesis and recapitulate features of syndromic ciliopathies. Hum Mol Genet 2015;24:3775-3791.
23. Lancaster MA, Gopal DJ, Kim J, et al. Defective Wnt-dependent cerebellar midline fusion in a mouse model of Joubert syndrome. Nat Med 2011;17:726-731.

24. Menotti-Raymond M, David VA, Schaffer AA, et al. Mutation in CEP290 discovered for cat model of human retinal degeneration. J Hered 2007;98:211-220.

25. Cideciyan AV, Aleman TS, Jacobson SG, et al Centrosomal-ciliary gene CEP290/NPHP6 mutations result in blindness with unexpected sparing of photoreceptors and visual brain: implications for therapy of Leber congenital amaurosis. Hum Mutat 2007;28:1074-1083.

26. Cideciyan AV, Hauswirth WW, Aleman TS, et al. Human RPE65 gene therapy for Leber congenital amaurosis: persistence of early visual improvements and safety at 1 year. Hum Gene Ther 2009;20:999-1004.

27. Petit L, Khanna H, Punzo C. Advances in gene therapy for diseases of the eye. Hum Gene Ther 2016;27:563-579.

28. Bainbridge JW, Smith AJ, Barker SS, et al. Effect of gene therapy on visual function in Leber's congenital amaurosis. N Engl J Med 2008;358:2231-2239.

29. Beltran WA, Cideciyan AV, Lewin AS, et al. Gene therapy rescues photoreceptor blindness in dogs and paves the way for treating human X-linked retinitis pigmentosa. Proc Natl Acad Sci U S A 2012;109:2132-2137.

30. MacLaren RE, Groppe M, Barnard AR, et al. Retinal gene therapy in patients with choroideremia: initial findings from a Phase 1/2 clinical trial. Lancet 2014;383:1129-1137.

31. Vandenberghe LH, Wilson JM, Gao G. Tailoring the AAV vector capsid for gene therapy. Gene Ther 2009;16:311-319.

32. Harper SQ, Hauser MA, DelloRusso C, et al Modular flexibility of dystrophin: implications for gene therapy of Duchenne muscular dystrophy. Nat Med 2002;8:253-261.

33. Gao GP, Sena-Esteves M. Introducing genes into mammalian cells: viral vectors. In: Green MR, Sambrook J, eds. Molecular Cloning, Vol 2: A Laboratory Manual. New York: Cold Spring Harbor Laboratory Press, 2012:1209-1313.

34. Rao KN, Zhang W, Li L, et al. Prenylated retinal ciliopathy protein RPGR interacts with PDE6delta and regulates ciliary localization of Joubert syndrome-associated protein INPP5E. Hum Mol Genet 2016;25:4533-4545.

35. Venkatesh A, Ma S, Langellotto $F$, et al. Retinal gene delivery by rAAV and DNA electroporation. Curr Protoc Microbiol 2013;Chapter 14:Unit 14D 4.

36. Wert KJ, Skeie JM, Davis RJ, et al. Subretinal injection of gene therapy vectors and stem cells in the perinatal mouse eye. J Vis Exp 2012 Nov 25 DOI: $10.3791 / 4286$

37. Li L, Anand M, Rao KN, et al. Cilia in photoreceptors. Methods Cell Biol 2015;127:75-92.

38. Murga-Zamalloa CA, Ghosh AK, Patil SB, et al. Accumulation of the Raf-1 kinase inhibitory protein (Rkip) is associated with Cep290-mediated photoreceptor degeneration in ciliopathies. J Bio Chem 2011:286:28276-28286.

39. Tsang WY, Bossard C, Khanna H, et al. CP110 suppresses primary cilia formation through its interaction with CEP290, a protein deficient in human ciliary disease. Dev Cell 2008;15:187-197.

40. Drivas TG, Holzbaur EL, Bennett J. Disruption of CEP290 microtubule/membrane-binding domains causes retinal degeneration. J Clin Invest 2013; 123:4525-4539.

41. Rachel RA, May-Simera HL, Veleri S, et al. Combining Cep290 and Mkks ciliopathy alleles in mice rescues sensory defects and restores ciliogenesis. J Clin Invest 2012;122:1233-1245.

42. Barbelanne M, Song J, Ahmadzai M, et al Pathogenic NPHP5 mutations impair protein interaction with Cep290, a prerequisite for ciliogenesis. Hum Mol Genet 2013;22:2482-2494.

43. Boye SE, Boye SL, Lewin AS, et al. A comprehensive review of retinal gene therapy. Mol Ther 2013;21:509-519.

44. Mookherjee S, Hiriyanna S, Kaneshiro K, et al. Long-term rescue of cone photoreceptor degeneration in Retinitis Pigmentosa 2 (RP2) Knockout mice by gene replacement therapy. Hum $\mathrm{Mol}$ Genet 2015;187:81-89.

45. Cheng T, Peachey NS, Li S, et al. The effect of peripherin/rds haploinsufficiency on rod and cone photoreceptors. J Neurosci 1997;17:8118-8128.

46. Maguire AM, Simonelli F, Pierce EA, et al. Safety and efficacy of gene transfer for Leber's congenital amaurosis. N Engl J Med 2008;358:2240-2248.

47. Hildebrandt F, Benzing T, Katsanis N. Ciliopathies. N Engl J Med 2011;364:1533-1543.

48. Downs LM, Scott EM, Cideciyan AV, et al. Overlap of abnormal photoreceptor development and progressive degeneration in Leber congenital amaurosis caused by NPHP5 mutation. Hum Mol Genet 2016;25:4211-4226.

49. Minella AL, Mowat FM, Willett KL, et al. Differential targeting of feline photoreceptors by recombinant adeno-associated viral vectors implications for preclinical gene therapy trials. Gene Ther 2014;21:913-920.

50. Cideciyan AV, Rachel RA, Aleman TS, et al. Cone photoreceptors are the main targets for gene therapy of NPHP5 (IOCB1) or NPHP6 (CEP290) blindness: generation of an all-cone Nphp6 hypomorph mouse that mimics the human retina ciliopathy. Hum Mol Genet 2011;20:1411-1423.

51. Han Z, Conley SM, Makkia RS, et al. DNA nanoparticlemediated ABCA4 delivery rescues Stargardt dystrophy in mice. J Clin Invest 2012;122:3221-3226.

52. Hashimoto T, Gibbs D, Lillo $C$, et al. Lentiviral gene replacement therapy of retinas in a mouse model for Usher syndrome type 1B. Gene Ther 2007;14:584-594.

Received for publication March 22, 2017 accepted after revision June 27, 2017

Published online: July 5, 2017. 